\title{
Pedagogia e literatura: crianças e bichos na literatura infantil de Clarice Lispector
}

\section{Pedagogy and literature: children and animals in Clarice Lispector's children books}

\author{
Nilson Fernandes Dinis*
}

\begin{abstract}
RESUMO
Este estudo apresenta uma reflexão das relações entre a literatura infantil e a educação ressaltando a singularidade dos textos de Clarice Lispector que desconstroem a relação hegemônica adulto-criança e privilegiam o mundo das crianças e dos bichos ao inverter os pressupostos pedagógicomoralizantes que sempre estiveram presentes neste gênero literário.

Palavras-chave: Clarice Lispector, literatura infantil, educação de crianças.
\end{abstract}

\begin{abstract}
This study presents some thoughts about the relationship between children literature and education to project the singularity of Clarice Lispector's texts deconstructing the hegemony adult-children and distinguishing children and animals world by the inversion of the moral-pedagogical motives that always have been conected to this kind of literary genre. Key-words: Clarice Lispector, children books, children education.
\end{abstract}

Professor adjunto na área de Psicologia da Educação no Departamento de Teoria e Fundamentos da Educação da Universidade Federal do Paraná. E-mail: nfdinis@hotmail.com 
E eis que escolhi um dia um livro chamado $O$ lobo da estepe, de Hermann Hesse. O título me agradou, pensei tratar-se de um livro de aventuras tipo Jack London. O livro, que li cada vez mais deslumbrada, era de aventura, sim, mas outras aventuras. E eu, que já escrevia pequenos contos, dos 13 aos 14 anos fui germinada por Hermann Hesse e comecei a escrever um longo conto imitando-o: a viagem interior me fascinava. Eu havia entrado em contato com a grande literatura (LISPECTOR, 1992, p. 491-492).

Ao falar de sua infância, a escritora brasileira Clarice Lispector se refere ao impacto causado pela leitura de $O$ lobo da estepe, do escritor Hermann Hesse, na sua própria literatura. O romance se tornou bastante conhecido pela crítica psicanalítica que incidiu sobre o romance e que via na história atormentada do personagem Harry Haller, dividido entre suas duas naturezas: a de homem e a de lobo, a encenação do tema do duplo na personalidade: o eterno conflito entre consciente e inconsciente ou mesmo entre o self e a sombra em uma leitura junguiana. E com isso esses leitores apressados esqueceram a mais preciosa lição do Tratado do Lobo da Estepe:

Tudo o que há de feroz dentre de si ele o atribui ao lobo [...] não é capaz de ver que fora do lobo, atrás do lobo, vivem no seu interior muitas outras coisas: que nem tudo o que morde é lobo; que dentro de si habitam também a raposa, o dragão, o tigre, o macaco e ave-do-paraíso, e que todo esse mundo é um éden cheio de milhares de seres, formosos e terríveis, grandes e pequenos, fortes e delicados, mundo asfixiado e cercado pelo mito do lobo - tanto com o verdadeiro homem que nele há é asfixiado e preso apenas pela sua aparência de homem, pelo burguês (HESSE, 1986, p. 70).

Portanto, em O lobo da Estepe vemos desenvolver-se não uma teoria do duplo, mas uma teoria do múltiplo: a rica fauna que habita cada ser humano. Não o palco do mal estar na civilização, com o sofrimento medíocre de um homem perdido na incapacidade de reconciliar suas duas naturezas, mas um novo exercício otimista de afirmação da Vida, um projeto multipersonalístico para o Homem. Porém, a unidade do eu ou a duplicidade entre um espaço subjetivo interno e externo são experiências tão evidentes em nossa cultura que dificilmente são colocadas em xeque. E esse é justamente um dos conceitos 
que o historiador Nobert Elias questionará em O Processo Civilizador ${ }^{1}$. É precisamente pela educação civilizadora, com o controle dos impulsos, que se dará o que chamaremos aqui de domesticação do múltiplo no uno, ou seja, a simplificação dos diversos matizes, impulsos e possibilidades de um indivíduo e toda sua caótica imprevisibilidade em uma forma una ou dupla, impondo, portanto, uma nova forma de viver e experimentar nossos próprios corpos.

Entretanto, não é uma solução definitiva e essa inquietude civilizatória entre viver os impulsos ou organizar-se em uma forma única, entre viver o múltiplo e o uno, entre o desejo de viver os fluxos ou o desejo de produzir uma essência, é uma questão ontológica retomada nos textos de Clarice Lispector, sendo um de seus temas fundamentais. O narrador não vive uma identidade, mas um constante jogo de metamorfoses sem fim que estão desconstruindo a noção de “eu”. Mas não será esse exatamente o lugar privilegiado de um escritor ou de um poeta?

$\mathrm{Na}$ visão do escritor Elias Canetti, um poeta é justamente um guardião das metamorfoses e é só pelo dom de metamorfosear-se no outro é que o poeta pode manter aberto em nosso mundo um espaço de comunicabilidade entre os homens ${ }^{2}$, abrir-se para os seres mais distintos e compreendê-los através de sua própria pele. E também não seriam metamorfoses as constantes séries animais que percorrem os textos clariceanos e que guardam ressonâncias com o romance de Hermann Hesse?

1 "O controle mais firme, mais geral e uniforme das emoções, característico dessa mudança civilizadora, juntamente com o aumento de compulsões internas que, mais implacavelmente do que antes, impedem que todos os impulsos espontâneos se manifestem direta e motoramente em ação, sem a intervenção de mecanismos de controle - são o que é experimentado como a cápsula, a parede invisível que separa o 'mundo interno' do indivíduo do 'mundo externo' ou, em diferentes versões, o sujeito de cognição de seu objeto, o 'ego' do outro, o 'indivíduo' da 'sociedade'. O que está encapsulado são os impulsos instintivos e emocionais, aos quais é negado acesso direto ao aparelho motor. Eles surgem na autopercepção como o que é ocultado de todos os demais, e, não raro, como o verdadeiro ser, o núcleo da individualidade. A expressão 'o homem interior' é uma metáfora conveniente, mas que induz em erro" (ELIAS, 1994, p. 246-247).

2 "Esta seria, creio, a verdadeira tarefa dos poetas. Graças a um dom que foi universal e hoje está condenado à atrofia, e que precisariam por todos os meios preservar para si, os poetas deveriam manter abertas as vias de acesso entre os homens. Deveriam ser capazes de se transformar em qualquer um, mesmo no mais ínfimo, no mais ingênuo, no mais impotente. Seu desejo íntimo pela experiência dos outros não poderia jamais se permitir ser determinado por aqueles objetivos que regem nossa via normal, oficial, por assim dizer: teria de ser absolutamente livre de toda pretensão de sucesso ou prestígio, ser uma paixão por si, a paixão justamente pela metamorfose" (CANETTI, 1990, p. 282). 
Não ter nascido bicho é uma minha secreta nostalgia. Eles às vezes clamam do longe muitas gerações e eu não posso responder senão ficando inquieta. É o chamado (LISPECTOR, 1993, p. 57).

Uma pantera negra enjaulada. Uma vez olhei bem nos olhos de uma pantera e ela me olhou bem nos meus olhos. Transmutamo-nos. Aquilo. Saí de lá toda ofuscada por dentro, o ' $\mathrm{x}$ ' inquieto. Tudo se passara atrás do pensamento. Estou com saudade daquele terror que me deu trocar de olhar com a pantera negra. Sei fazer terror (LISPECTOR, 1993, p. 85).

Quero que me perdoem eu ser tão cheia de sensualidade que é um grito animal dentro de mim, um gosto de voz aguda de lobo desejando a presa, eu! eu que aspiro à grande desordem dos desejos vis e as trevas que me possuem no orgasmo apocalíptico de meu existir (LISPECTOR, 1978, p. 136).

É também essa constante disposição para as metamorfoses que encontraremos mesmo nos textos de Clarice Lispector para a infância. É aqui que duplamente o narrador torna-se criança e torna-se também bicho ${ }^{3}$. Se tornarse criança é a forma que permite ao narrador clariceano afastar-se da hegemonia do olhar adulto, tornar-se bicho é também um dispositivo que permite afastar-se da hegemonia do mundo racional do humano. Expondo seu corpo aos diversos fluxos que habitam o mundo dos bichos e das crianças, o narrador, antes humano e adulto, tenta aproximar-se da vida de uma forma mais direta e instintiva. Assim a literatura infantil de Clarice Lispector não quer dar lições de moral, nem adultizar ou socializar a criança, quer proporlhe uma nova aventura: a experimentação de um novo mundo que pode ser constantemente recriado pela imaginação.

Como a própria autora nos diz, na única entrevista televisiva para a TV Cultura, a idéia de escrever literatura infantil começa quando a mesma estava em Nova York e seu filho lhe pede uma estória. Ela interrompe o livro que estava escrevendo, A maçã no escuro, e escreve em inglês $O$ mistério do Co-

3 Para NUnEs (1995, p. 132): "Os animais gozam, no mundo de Clarice Lispector, de uma liberdade incondicionada, espontânea, originária, que nada - nem a domesticação degradante de uns, nem a aparência frágil e indefesa de outros - seria capaz de anular". É no exercício dessa liberdade incondicionada que acreditamos que também se insira a presença da infância nos textos da autora. Por não ter ainda adestrados os instrumentos da racionalidade que se impõem no processo civilizatório, a infância é o reino da espontaneidade e da liberdade de uma experimentação vital e direta do mundo, descomprometida com os limites e preconceitos do olhar adulto e seus mecanismos de defesa que impedem sempre de atingir a realidade de uma forma imediata e autêntica. 
elho Pensante, que a pedido de um editor foi traduzido para o português e publicado em 1967. Mais tarde Clarice ainda publica para o leitor infantil: $A$ Mulher que matou os peixes, A vida íntima de Laura e Quase de verdade. ${ }^{4}$ Mas falar de uma literatura especificadamente infantil talvez não seja apropriado para uma escritora transgressora como Clarice, escritora que já dissera provocativamente: "Inútil querer me classificar: eu simplesmente escapulo não deixando, gênero não me pega mais" (LISPECTOR, 1993, p.17).

E é justamente pelo não enquadramento no formato tradicional da literatura infantil é que seus textos são singulares. A originalidade dos textos infantis de Clarice Lispector está em sua provocação ao leitor infantil enredando-lhe em enigmas que contribuem na elaboração de novos caminhos para o conhecimento. Ao renunciar ao ponto de vista hegemônico e omnisciente do narrador adulto e ao mostrar todas as suas hesitações e fragilidades, seus textos renunciam ao aspecto normativo tão presente na produção deste gênero de literatura para crianças.

É o que parece ocorrer em $O$ Mistério do Coelho Pensante. A história é bastante simples e nela temos um coelho branco chamado Joãozinho que só pensava mexendo bem depressa o nariz. Pensando ou franzindo o nariz, ele consegue achar um meio de fugir das grades da sua casinhola quando the faltava comida. Porém aos poucos o coelho aprende também a gostar de fugir por fugir: "E passou a fugir sem motivo nenhum: só mesmo por gosto". O problema proposto pelo livro é tentar entender não o porquê, mas como o coelho fugia. E é este problema que a narradora procura dividir com o seu leitor já que também não tem a solução:

Você na certa está esperando que eu agora diga qual foi o jeito que ele arranjou para sair de lá. Mas aí é que está o mistério: não sei!

$\mathrm{E}$ as crianças também não sabiam. Pois como eu lhe disse, o tampo (da porta da casinhola) era de ferro pesado. Pelas grades? Lembre-se de que Joãozinho era um gordo e as grades eram apertadas (LISPECTOR, 1981) .

4 A existência ou não de uma literatura especificadamente infantil tem sido tema de debate de muitos especialistas. Uma das posições mais coerentes que conhecemos é a da escritora Cecília Meireles: "São as crianças na verdade que o delimitam, com sua preferência. Costuma-se classificar como Literatura Infantil o que para elas se escreve. Seria mais acertado, talvez, assim classificar o que elas lêem com utilidade e prazer. Não haveria pois uma Literatura Infantil a priori, mas a posteriori” (MEIRELES, 1984, p. 20). 
A grande marca do texto é o uso extremo da oralidade por ser um texto dirigido inicialmente ao seu filho Paulo. Mas, já na nota inicial do livro, a autora destaca a participação de todos aqueles que serão responsáveis pela leitura de seu texto para as outras crianças: "Como a história foi escrita para exclusivo uso doméstico, deixei todas as entrelinhas para as explicações orais. Peço desculpas a pais e mães, tios e tias, e avós, pela contribuição forçada que serão obrigados a dar. Mas pelo menos posso garantir, por experiência própria, que a parte oral desta história é o melhor dela" (LISPECTOR, 1981).

Essa função dialógica do texto na busca de um contato maior com o leitor também será a marca predominante de seus outros textos para a infância e que será logo incorporada em sua literatura para adultos. Provocado diretamente pelo narrador, o leitor infantil se vê então preso em um mundo de signos estranhos a decifrar. Nasce aqui a possibilidade de um novo exercício do pensamento. Ao contrário dos outros contos tradicionais, nos quais o final da história busca a solução do problema levantado no decorrer do enredo, aqui o mistério persiste e a narradora convida o próprio leitor a pensar como o coelho Joãozinho, ou seja, torna-se também um coelho (um exercício de metamorfose?) franzindo o nariz bem depressa para tentar descobrir a solução do mistério:

Se você quiser adivinhar o mistério, Paulinho, experimente você mesmo franzir o nariz para ver se dá certo. É capaz de você descobrir a solução, porque menino e menina entendem mais de coelho do que pai e mãe. Quando você descobrir, você me conta. Eu é que não vou mais franzir meu nariz, porque já estou cansada, meu bem, de só comer cenoura (LISPECTOR, 1981).

Forçada a pensar, a criança se vê em contato com um mundo de novas possibilidades existenciais. Tal literatura passa a exercer um papel bastante importante para a criança que em seus primeiros anos escolares está sendo moldada para os valores dominantes da razão, da ordem e do pensamento lógico, levando o leitor a resgatar o seu espaço lúdico. Assim percebemos, mesmo nos contos infantis de Clarice Lispector, um processo de experimentação do pensamento que, questionando as formas tradicionais do que é considerado "pensar", nos leva a buscar com a autora um novo caminho para o exercício do pensamento. Mas o objetivo do texto clariceano é mais um vez a busca de um novo espaço de liberdade, é tentar fugir como o coelho do apri- 
sionamento de uma forma. Livrar-se dos medos, dos receios, livrar-se da "terceira perna”. Deslocar o corpo, inverter sensações, experimentar sempre mais, metamorfosear-se em coelho, produzir, por exemplo, um nariz pensante. Brincar ludicamente com o mundo, com as palavras, com o corpo e com o próprio pensamento.

Já no conto infantil A mulher que matou os peixes, publicado em 1968, podemos observar uma construção semelhante. A marca da oralidade também aparece nas primeiras linhas do texto onde o narrador já tenta estabelecer uma ligação direta com seu leitor: "Essa mulher que matou os peixes infelizmente sou eu. Mas juro a vocês que foi sem querer. Logo eu! que não tenho coragem de matar uma coisa viva. Até deixo de matar uma barata ou outra" (LISPECTOR, 1991). Porém a estória do crime é apenas um pretexto para prender o leitor e é adiada ao máximo no decorrer do enredo: "Não tenho coragem ainda de contar agora mesmo o que aconteceu. Mas prometo que no fim deste livro contarei e vocês que vão ler esta história triste me perdoarão ou não".

Antes de confessar seu crime, a narradora passa ao que parece ser o objetivo principal do livro, essa mulher quase-bicho ${ }^{5}$ descreve toda uma incursão pelo mundo dos bichos que teve durante toda sua vida na tentativa de provar sua inocência no caso da morte dos peixinhos e só então pedir perdão a seus leitores. A narradora, no intuito de aproximar ainda mais de seu leitor, se desnuda ao se identificar pelo próprio nome da autora: "Antes de começar, quero que vocês saibam que meu nome é Clarice. E vocês, como se chamam? Digam baixinho o nome de vocês e o meu coração vai ouvir". Já instalada confortavelmente na primeira pessoa, Clarice vai nos contando a história de alguns dos seus bichos como a macaquinha doente Lisette, os pintinhos que dera aos seus filhos de presente, o cachorro Dilermando comprado por ela em Nápoles, o cachorro Jack que teve em Washington, os gatos que teve na infância e até mesmo a história de ratos, baratas e lagartixas que são os "bichos naturais", ou seja, "aqueles que a gente não convidou nem comprou".

Leitores adultos e familiarizados com os temas pueris da literatura infantil podem se sentir constrangidos com a presença de algumas cenas de violência que aparecem ao longo do texto. Entre elas "uma história tão terrível que até parece filme de mocinho e bandidos": a estória da morte violenta

5 "Hoje fui entrevistada por quatro menininhas de 11 anos com fotografias \& perguntas \& perguntas \& perguntas, por causa da estória da mulher que matou os peixes. E se era verdade que eu gostava de bichos. E disse é claro. Também sou bicho" (NUNES, 1988, p. 298). 
dos cachorros Bruno e Max que, de uma amizade solidária, passam ao ódio mais feroz. Bruno e Max eram tão amigos que "um chamava o outro, convidando para almoçar e botavam os dois focinhos no mesmo prato de comida". Mas em uma de suas visitas a Bruno, Max resolve fazer umas "festinhas" em Roberto, dono de Bruno, e este, pensando que Max iria atacar seu dono, corre em sua defesa atacando ferozmente seu amigo. Bruno sai da luta gravemente ferido e tempos depois, já recuperado, resolve vingar-se de Max. E desta vez ele estava com tanta raiva, "tanta raiva que sua força aumentou e ficou diabólica" resultando no assassinato de Max. Mas o mundo dos cachorros também tem suas próprias leis o que culmina na execução de Bruno morrendo estraçalhado pelos cachorros da vizinhança.

Além da morte violenta de Bruno e Max, o texto tematiza outras mortes, como a morte dos peixinhos vermelhos que serve de pretexto à estória, a morte de ratos e baratas, a morte por doença da macaquinha Lisette e também a ameaça de morte sofrida por Jack de um vizinho incomodado com seus latidos. Mas a história de Bruno e Max se destaca das outras por ser também "uma história de grande amor": "Bruno amava tanto Roberto que não permitia nenhum outro cachorro fazer carinho no dono ou atacá-lo. Também era grande o amor fraterno que ligava Bruno a Max. Mas o primeiro amor era para Roberto" (LISPECTOR, 1991).

Ao final da estória a narradora finalmente confessa seu crime: seu filho fora viajar por um mês deixando ao seus cuidados dois peixinhos vermelhos, mas a narradora, ocupada também em escrever "histórias para gente grande", esqueceu de alimentá-los por três dias e, como peixe é "tão mudo como uma árvore e não tinha voz para reclamar e me chamar", acabaram morrendo de fome. Portanto o crime da narradora, como o crime do cachorro Bruno, é também um crime por amor, amor incondicional à sua produção literária que acaba, por esquecimento, lhe afastando dos seus afazeres domésticos. No final do conto a estória do crime é elucidada, porém restará ao leitor mais um problema não solúvel, perdoar ou não perdoar o crime: "Eu peço muito que vocês me desculpem. Dagora em diante nunca mais ficarei distraída. Vocês me perdoam?" (LISPECTOR, 1991).

Já em A vida íntima de Laura, publicado em 1974, o título, que cria a expectativa de um texto psicológico, traz mais uma surpresa: Laura é apenas uma galinha "simpática" e "bem burrinha", mas é também a campeã de seu quintal e da vizinhança em matéria de botar ovos. Embora não haja uma identificação explícita da autora como nos textos anteriores, mais uma vez ela dirige-se ao seu leitor: 


\begin{abstract}
Vou logo explicando o que quer dizer "vida íntima". É assim: vida íntima quer dizer que a gente não deve contar a todo mundo o que se passa na casa da gente. São coisas que não se dizem a qualquer pessoa. Pois vou contar a vida íntima de Laura.

Agora adivinhe quem é Laura.

Dou-lhe um beijo na testa se você adivinhar. E duvido que você acerte!

Dê três palpites. Viu como é difícil?

Pois Laura é uma galinha.

E uma galinha muito da simples (LISPECTOR, 1974).
\end{abstract}

Ironicamente, mesmo sendo "burrinha", Laura, com seus "pensamentozinhos" e "sentimentozinhos", recorre a várias artimanhas que lhe permitem escapar da panela. Para escapar da morte, a galinha usa da mesma sensibilidade do narrador ao metamorfosear-se no outro. Laura "gostava muito de viver", sendo reconhecida apenas por ser a mais limpa e a mais bem penteada de seu galinheiro, resolve então meter o bico na lama se lambuzando toda, o que a salva imediatamente da morte, quando a confundem com Zeferina, "prima de quarto grau de Laura".

Talvez Laura e Zeferina sejam também primas de Pedrina e Petronilha, personagens do conto "Uma história de tanto amor", publicado em A legião estrangeira. Pedrina e Petronilha têm o mesmo destino de Zeferina ao serem devoradas em um banquete totêmico regado ao molho pardo. No entanto, como nos diz uma das personagens desse conto para adultos: "Quando a gente come bichos, os bichos ficam mais parecidos com a gente, estando assim dentro de nós" (LISPECTOR, 1977, p. 149). Mas Laura, por ser também "uma galinha para frente", pode escapar do destino trágico de suas primas por contar inclusive com a proteção sobrenatural de Xext, um dos habitantes de Júpiter que intervêm na narrativa para conhecer Laura e salvá-la. De todos os habitantes da Terra, Laura é a escolhida de Xext por não ser "quadrada". Portanto, bem diferente da perspicaz descrição dos humanos feita por Laura: "-Ah, cacarejou Laura, os humanos são muitos complicados por dentro. Eles até sentem obrigados a mentir, imagine só".

Humanos "complicados" e "mentirosos", a mesma "gente grande" e "chata" descrita pela narradora em A mulher que matou os peixes. Sempre os adultos para os quais, às vezes, a narradora também é obrigada a mentir: "Só minto às vezes para certo tipo de gente grande porque é o único jeito. Tem gente grande que é tão chata! Vocês não acham? Elas nem compreendem a alma de criança. Criança nunca é chata" (LISPECTOR, 1991). Por meio do pac- 
to de verdade que estabelece com o leitor infantil o narrador tenta distanciar do olhar hegemônico humano e adulto criando um estado de cumplicidade! É assim que aos poucos aproveita-se também para perversamente desnudar todas as armadilhas do pensamento lógico-racional do adulto, ao mesmo tempo envenenando o leitor infantil com seu mundo de incertezas: "Você sabe que Deus gosta de galinha? E sabe como é que eu sei que Ele gosta? É o seguinte: se Ele não gostasse de galinha Ele simplesmente não fazia galinha no mundo. Deus gosta de você senão Ele não fazia você. Mas por que faz ratos? Não sei” (LISPECTOR, 1974) ${ }^{6}$.

Sobre os contos infantis de Clarice Lispector é também importante destacar que eles se afastam do modelo de conto infantil com o seu tradicional "era uma vez", que remetia o leitor a um tempo e a um espaço distanciado fundamentando a omnisciência de seu narrador. A autora se dizia incapaz de tal construção por já saber que seus textos não se enquadravam nas estórias convencionais com seus enredos lineares povoados de "fatos necessários a uma história". Dos livros infantis que escreveu, a única exceção poderia estar presente em Quase de verdade, publicado postumamente em 1978, portanto, um ano após a morte da escritora.

O pretexto para a estória são as aventuras de Ulisses, o cachorro de Clarice, que assume desde o início a posição de narrador. Mas ironicamente o estilo do "era uma vez" é quebrado pelo próprio narrador, Ulisses, ao se apresentar como sendo o cachorro de Clarice, ao mesmo tempo desnudando mais uma vez o autor do texto, a própria Clarice, guardiã das metamorfoses, a única conhecedora da linguagem dos animais que é escolhida como a tradutora da estória latida de Ulisses para os seus leitores:

Era uma vez... Era uma vez: eu! Mas aposto que você não sabe quem eu sou. Prepare-se para uma surpresa que você nem adivinha. Sabe quem eus sou? Sou um cachorro chamado Ulisses e minha dona é Clarice. Eu fico latindo para Clarice e ela - que entende o significado dos meus latidos - escreve o que eu lhe conto (LISPECTOR, 1978).

6 Nesse sentido, o texto de Clarice para as crianças guarda ressonâncias com seus textos para adultos nos quais o narrador já tentava desconstruir o pensamento lógico-racional: "Que mal porém tem eu me afastar da lógica?" (LISPECTOR, 1993, p. 17). 
Porém essas primeiras linhas, ao invés de produzirem o efeito de distanciamento em um mundo longínquo como o "era uma vez" clássico, produzem um contato direto entre narrador e leitor no presente e ao mesmo tempo lhe convidam novamente a um mundo de surpresas e expectativas. A estória são as observações latidas de Ulisses após ter feito uma viagem ao quintal de Onofre e Oníria: os proprietários de uma grande quintal com galos, galinhas e uma figueira "que não se sabe por que nunca dera frutos".

Em um dia de domingo, "sem nenhum programa, sem nenhum divertimento, era um dia de nada", a figueira, invejosa da fertilidade das galinhas do quintal, resolve por vingança apropriar-se dos seus ovos para "enriquecer à custa dos outros", contando para isso com os feitiços de Oxélia, uma nuvem preta que era uma bruxa má. Graças ao feitiço de Oxélia as folhas da figueira brilhavam mesmo durante a noite e as galinhas pensando que ainda era dia punham ovos sem parar. Mas com a intervenção de Ovídio e Oníria, que "eram como o rei e a rainha do galinheiro", as aves fazem uma rebelião contra a "figueira ditadora"7 conseguindo reverter o feitiço de Oxélia. Após uma boa noite de sono, da qual "estavam precisados depois de tantas noite de insônia", resolvem fazer uma festança para comemorar sua libertação. E aqui o narrador aproveita também para explicar como as aves perderam seus dentes ao tentar morder os pirulitos que Ovídio e Odisséia compraram para a festa: "Acontece, porém, que elas não sabiam que pirulito é para ser chupado ou lambido e começaram a mordê-lo: crack, crack, crack com os dentes. O que aconteceu? aconteceu que os dentes se quebraram todos. É por isso que as aves não têm dentes. Pelo menos é isso que eu penso" (LISPECTOR, 1978).

Já sem os dentes, as aves visitam outras terras na busca de uma comida nova que não precisasse ser mastigada. E mais uma vez entra no texto a intervenção mágica da bruxa Oxalá que, ao contrário de Oxélia, era "uma bruxa muito da boa". Guiando os bichos pela mata, Oxélia lhes apresenta um pé de jabuticaba e as aves se deliciaram ao pisar nas suas frutas maduras e redondas com um barulho gostoso: plóqui-ti-ti, plóqui-ti-ti, plóqui-ti-ti. Mas ao deliciar a fruta se defrontam com mais um problema: deve-se ou não engolir o caroço? Até pensaram em pedir novamente a ajuda de Oxalá mas acharam que já tinham pedido muito e resolveram se virar sozinhos. Como nos outros textos de Clarice, mais uma vez resta ao leitor um problema, resolver o enigma de uma sentença quase que hamletiana: "Engole-se ou não se engole o caroço?".

7 ARÊAS (1997-8, p. 149) chama a atenção para o fato do livro ter sido escrito nos anos 70, portanto, em "anos ditatoriais". 
$\mathrm{Eu}$, que sou cachorro, não sei o que responder às aves.

Engole-se ou não se engole o caroço?

Você, criança, pergunte isso à gente grande.

Enquanto isso, eu digo: $-\mathrm{Au}, \mathrm{au}, \mathrm{au}$ !

E Clarice entende que eu quero dizer:

Até logo, criança! Engole-se ou não se engole o caroço?

Eis a questão (LISPECTOR, 1978).

Mas imagens de animais já são uma tradição na literatura infanto-juvenil presente desde as fábulas e os contos de fadas. Depositária do olhar do outro, dos mitos e crenças do mundo adulto, a infância sempre foi vista como um espaço a ser modelado, educado, disciplinado. Portanto, a tradição literária infantil nasce do desejo de educar essa mesma infância com o caráter pedagógico-moralista de seus textos comprometidos com a manutenção da ordem social. É assim que os bichos apareceram nos contos infantis como formas antropomórficas de simbolizar as vivências e a interioridade frágil das crianças, vistas através do olhar adulto, e preparar o processo de disciplinarização para sua inserção no mundo civilizado adulto e humano.

"Conheci um 'ela' que humanizava bicho conversando com ele e emprestando-lhe as próprias características. Não humanizo bicho porque é ofensa - há que respeitar-lhe a natureza - eu é que me animalizo" já dizia o narrador clariceano em Água Viva (1991, p. 54). Também podemos dizer com a autora que conhecemos muitos "eles" e "elas" na literatura infantil que antropomorfizam os bichos no intuito de produzir uma literatura com fins disciplinadores. Essa também foi uma das tendências da literatura infantil brasileira dos anos 40 e 50, conforme as análises de LAJOLO e ZILBERMAN (1985), na qual a preocupação com a qualidade estética dos textos cede lugar a uma preocupação moralista-educativa. Bichos ou bonecos animados aparecem nos contos infantis brasileiros como projeção dos conteúdos infantis e a serviço da pedagogia adulta que, desta forma, impõe sua visão de mundo à infância resultando em um processo que as autoras chamam de "infantilização da criança", ou seja, a "projeção de uma imagem ideal da criança, pautada pelas expectativas do adulto, que a reduziu à condição pueril e à indigência afetiva e intelectual".

Um dos exemplos citado pelas autoras é o personagem Cachorrinho Samba, do livro homônimo de Maria José Dupré, que, ao sair de casa e se perder, simboliza a criança que recebe punição por sua desobediência ao mundo 
adulto $^{8}$. Certamente o Cachorrinho Samba não tem nenhuma correspondência com Ulisses, o cachorro de Clarice, que aparece como narrador em Quase de verdade. Ulisses se orgulha da liberdade que lhe permite fazer exatamente o que quer, além de não receber nenhuma punição por suas aventuras no quintal de Onofre e Oníria ou por suas traquinagens na casa de Clarice: "Sou um pouco malcriado, não obedeço sempre, gosto de fazer o que eu quero, faço xixi na sala de Clarice" (LISPECTOR, 1978). E mesmo em A mulher que matou os peixes, ao tentar descrever Jack, o cachorro americano que teve quando morou em Washington, Clarice já faz referência bastante clara à liberdade animal que tanto a fascina comparando-a ao mesmo tempo com a liberdade restrita do humano: "Ele tinha uma vida muito animada porque ele gostava de tudo o que fazia, igual a mim porque eu faço várias coisas na vida e gosto do que eu faço. Muitas coisas eu faço sem gostar, só por dever" (LISPECTOR, 1991).

O mesmo conflito está nas preocupações que perpassam o mundo da criança em idade escolar que entra em contato com os textos de Clarice Lispector, já que essa criança está sendo socializada para a internalização das regras do mundo adulto com a perda do prazer lúdico e sua inserção em um sistema no qual muitas vezes terá que fazer o que não gosta. No entanto, pensamos que a grande contribuição dos textos de Clarice Lispector está mesmo na escuta que dá ao mundo dos afetos, da imaginação, da criatividade; enfim, do desejo da criança: "Se vocês gostam de escrever ou desenhar ou dançar ou cantar, façam porque é ótimo, enquanto a gente brinca assim, não se sente mais sozinha, e fica de coração quente" (LISPECTOR, 1991). Clarice parece nos dizer que além, muito além dos processos exatos da matemática e das regras corretas da boa gramática, existe o mundo dos afetos, que rompe com o mundo frio das palavras, tentando atingir diretamente $o$ "coração quente" do leitor.

Ao mesmo tempo em que desenvolve temas complexos, a literatura de Clarice é também uma literatura que utiliza uma linguagem simples, mas não

8 "O texto exemplifica as duas características da ficção que recorre a animais como assunto e personagem: a) o cão simboliza a criança; mais que isso: dá vazão a uma imagem de infância que a considera uma faixa etária e desprotegida, necessitando amparo permanente e cuidados suplementares. Postula as incompetências da criança para cuidar de si mesma e justifica a intervenção constante do adulto na vida dela; b) o texto assume uma postura, já que aproveita a ocasião para transmitir ensinamentos morais e incutir atitudes, pregando principalmente a obediência" (LAJOLO; ZILBERMAN, 1985, p. 112). 
a linguagem trivial e infantilizada de grande parte das produções literárias voltadas para a infância. Portanto uma produção literária que se distingue da linguagem "edulcorada" da literatura infantil já denunciada ironicamente pelo poeta Carlos Drummond de Andrade ${ }^{9}$. Mas a crítica contundente do poeta à idéia de uma literatura infantil, não impediu que sua percepção sensível soubesse ao mesmo tempo diferenciar e apreciar a publicação do primeiro texto de Clarice para crianças: $O$ mistério do coelho pensante:

E diziam aqui na minha rua que Clarice Lispector é escritora difícil, custa-se a penetrar nos seus romances e contos por excesso de sutileza, de confusa dramaticidade interior. Aconselho - aconselho não, intimo quem assim julga, a conviver com o coelho pensante. Através deste texto - oral delicioso, que só um fabulista de primeiro time era capaz de compor: tudo entra pelos olhos, pelo coração e pela consciência da gente. Não há uma palavra em falso. Medida. Graça. Profundidade, sob a leve alegoria (ANDRADE, 1967, p. 6).

Mesmo LAJOLO e ZILBERMAN (1985) já destacavam a inovação trazida por Clarice Lispector na literatura infantil de seu tempo, desmascarando todas as inseguranças e as hesitações do narrador que, desta forma, atenua a assimetria entre o mundo da criança e o mundo do adulto. Portanto Clarice torna-se uma inovadora por incorporar mesmo na literatura infantil os dilemas e a fragmentaridade do narrador tão explorados na literatura adulta de vanguarda.

Assim a literatura de Clarice Lispector talvez colabore em dois âmbitos. Primeiro que sua produção para crianças, ao se distanciar dos preconceitos de uma visão autoritária e preconcebida do adulto sobre a infância, torna-se uma espécie de cartografia do mundo afetivo espontâneo e vital da criança, ou seja, pela literatura de Clarice conhecemos um pouco mais da dinâmica do

9 "Há uma tristeza cômica no espetáculo desses cavalheiros amáveis e dessas senhoras não menos gentis, que, em visita a amigos, se detêm a conversar com as crianças de colo, estas inocentes e sérias, dizendo-lhes toda a sorte de frases em linguagem infantil, que vem a ser a mesma linguagem de gente grande, apenas deformada no final das palavras e edulcorada na pronúncia... Essas pessoas fazem oralmente, e sem o saber, literatura infantil" (ANDRADE, 1994, p. 221). 
mundo da criança. Longe do absolutismo da visão lógica adulta, a infância torna-se aqui lugar de celebração da Vida. O segundo âmbito talvez atinja diretamente o coração quente do leitor. Na literatura infantil de Clarice Lispector, o leitor é incorporado à trama e é a ele que a autora se dirige de forma direta em seus livros solicitando sua presença para adivinhar coisas, inventar histórias, responder perguntas, convidando-o sempre para uma nova descoberta do mundo, no qual ele possa aguçar sua criatividade experimentando o mundo sempre de inúmeras maneiras.

Como vimos, bichos também estão presentes na maioria dos textos da autora, seja nos textos dirigidos a crianças, seja nos textos dirigidos aos adultos. Uma legião dos mais diferentes bichos: coelhos, gatos, peixes, búfalos, panteras, cachorros, cavalos e galinhas. São formas de Clarice sair de Clarice. Escrever em Clarice é sempre viver a multiplicidade de outros que a mediocridade de uma única vida não comporta. Clarice Lispector, esta escritora menina, nos faz então acreditar em um novo mundo perpassado de novas potencialidades ontogenéticas, novas possibilidades existenciais, resgatando o prazer lúdico na nossa forma de entrar em contato com o mundo. Clarice, essa mulher-menina, ao se aproximar do mundo dos bichos e das crianças torna-se múltipla, um cenário com os mais diversos e ricos seres que ecoam através de sua arte. Um exercício transbordante de uma vida que, por intermédio da arte, supera a angústia da unidade ou de uma duplicidade da essência humana na celebração de uma polaridade múltipla que transborda os limites do seu tempo, da linguagem, do pensamento e do próprio corpo do narrador e do leitor. Mais uma vez, travessuras de uma escritora-menina. Escritora que, mesmo em seus textos para adultos, um dia já dissera ser caleidoscópica: "Esta palavra a ti é promíscua? Gostaria que não fosse, eu não sou promíscua. Mas sou caleidoscópica: fascinam-me as minhas mutações faiscantes que aqui caleidoscopicamente registro" (LISPECTOR, 1993, p. 38).

\section{REFERÊNCIAS}

ANDRADE, C. D. Coelho pensante. Correio da Manhã, Rio de Janeiro, n. 22.884, p. 6, 10 nov. 1967.

ANDRADE, C. D. Literatura infantil. In: Confissões de Minas. Rio de Janeiro: Americ., 1944. p. 220-221. 
ARÊAS, V. Children's corner. Revista USP, São Paulo, n. 36, p. 145-153, dez./fev. 1997-98.

LISPECTOR, C. Água viva. Rio de Janeiro: Francisco Alves, 1993.

. Como nasceram as estrelas: doze lendas brasileiras. Rio de Janeiro: Nova Fronteira, 1987.

. A descoberta do mundo. Rio de Janeiro: F. Alves, 1992.

. A Legião Estrangeira. São Paulo: Ática, 1977.

. O mistério do coelho pensante. Rio de Janeiro: Rocco, 1981.

. A maçã no escuro. Rio de Janeiro: Paz e terra, 1974.

. A mulher que matou os peixes. Rio de Janeiro: F. Alves, 1991.

. Para não esquecer. São Paulo: Círculo do Livro, 1980.

. A paixão segundo G. H. Rio de Janeiro: Nova Fronteira, 1986.

. Quase de verdade. Rio de Janeiro: Rocco, 1978.

. Um sopro de vida: pulsações. Rio de Janeiro: Nova Fronteira, 1978.

. A vida íntima de Laura. Rio de Janeiro: J. Olympio, 1974.

NUNES, B. O drama da linguagem: uma leitura de Clarice Lispector. São Paulo: Ática, 1995.

NUNES, B. (Coord.). A paixão segundo G. H., edição crítica. Brasília: CNPq, 1988.

CADERMATORI, L. O que é Literatura Infantil. São Paulo: Brasiliense, 1986.

CANETTI, E. A consciência das palavras: ensaios. São Paulo: Cia. das Letras, 1990.

COELHO, N. N. A literatura infantil: história, teoria, análise (das origens orientais ao Brasil de hoje). São Paulo: Quíron, 1981.

ELIAS, N. O processo civilizador. Rio de Janeiro: J. Zahar, 1994. v. 1.

HESSE, H. O lobo da estepe. Rio de Janeiro: Record, 1986.

LAJOLO, M.; ZILBERMAN, R. Literatura infantil brasileira: história \& histórias. São Paulo: Ática, 1985.

MEIRELES, C. Problemas de literatura infantil. Rio de Janeiro: Nova Fronteira, 1984.

ZILBERMAN, R. A literatura infantil na escola. São Paulo: Global, 1985. 